\title{
Lower risk of hip fractures among Swedish women with large hips?
}

\author{
S. Klingberg ${ }^{1,2}$ (D) $\cdot$ K. Mehlig $^{1} \cdot$ V. Sundh ${ }^{1,3} \cdot$ B. L. Heitmann ${ }^{4,5,6} \cdot$ L. Lissner $^{1}$
}

Received: 31 May 2017 / Accepted: 21 December 2017 / Published online: 27 January 2018

(C) The Author(s) 2018. This article is an open access publication

\begin{abstract}
Summary In women, a large hip circumference (HC) related to lower hip fracture risk, independent of age and regardless if HC was measured long before or closer to the fracture. In older women, body mass index (BMI) explained the protection. Introduction In postmenopausal women, $\mathrm{HC}$ has been suggested to inversely associate with hip fracture while this has not been investigated in middle-aged women. We examined the association between HC, measured at two different time points, and hip fracture in a Swedish female population-based sample monitored for incident hip fractures over many years.

Methods Baseline HC, measured in 1968 or 1974 ( $n=1451$, mean age 47.6 years), or the HC measures that were the most proximal before event or censoring ( $n=1325$, mean age 71.7 years), were used to assess the effects of HC on hip fracture risk in women participating in the Prospective Population Study of Women in Gothenburg. HC was parameterized as quintiles with the lowest quintile (Q1) as reference. Incident hip fractures over 45 years of follow-up $(n=257)$ were identified through hospital registers.

Results Higher quintiles of $\mathrm{HC}$ at both baseline and proximal to event were inversely associated with hip fracture risk in ageadjusted models, but only baseline $\mathrm{HC}$ predicted hip fractures independently of BMI and other covariates (HR $(95 \% \mathrm{CI}) \mathrm{Q} 2,0.85$ (0.56-1.27); Q3, 0.59 (0.36-0.96); Q4, 0.57 (0.34-0.96); Q5, 0.58 (0.31-1.10)).

Conclusions A large $\mathrm{HC}$ is protective against hip fracture in midlife and in advanced age, but the association between proximal $\mathrm{HC}$ and hip fracture was explained by concurrent BMI suggesting that padding was not the main mechanism for the association. The independent protection seen in middle-aged women points to other mechanisms influencing bone strength.
\end{abstract}

Keywords Body mass index $\cdot$ Hip circumference $\cdot$ Hip fractures $\cdot$ Longitudinal

Electronic supplementary material The online version of this article (https://doi.org/10.1007/s00198-017-4363-y) contains supplementary material, which is available to authorized users.

S. Klingberg

sofia.klingberg@gu.se

1 Department of Public Health and Community Medicine, Section for Epidemiology and Social Medicine (EPSO), Institute of Medicine, Sahlgrenska Academy, University of Gothenburg, P.O Box 454, 405 30 Gothenburg, Sweden

2 Division of Pediatrics, Department of Clinical and Experimental Medicine, Linköping University, Linköping, Sweden

3 Geriatric Medicine, Department of Internal Medicine and Clinical Nutrition, Institute of Medicine, Sahlgrenska Academy, University of Gothenburg, Gothenburg, Sweden

4 Research Unit for Dietary Studies, The Parker Institute and the Institute of Preventive Medicine, Bispebjerg and Fredriksberg Hospitals, The Capital Region, Denmark

5 National Institute of Public Health, University of Southern Denmark, Copenhagen, Denmark

6 The Section for General Medicine, Department of Public Health, University of Copenhagen, Copenhagen, Denmark

\section{Introduction}

Scandinavian countries show the highest hip fracture incidence in the world, and older women are particularly affected [1]. Due to the continuous rise in life expectancy, the number of hip fractures is likely to increase further in the decades to come. Hip fractures are associated with disability, serious complications including cardiovascular and cognitive complications, and premature death [2]. Identifying protective and risk factors is a prerequisite for prevention. Interest in external hip protection devices for prevention of hip fractures, usually as underwear with pads on the outside of the hip, was raised in the 1980-1990s. However, hip protectors have not been found to reduce the risk of hip fractures in home-living older people, while a marginal protection in older people in nursing or residential homes has been observed [3]. Acceptance to wear such hip protectors has however been reported to be low [3].

Still, different anthropometric measures have been shown to associate with the risk of hip fracture, including both body 
size and body shape. Low body mass index (BMI) is a risk factor for osteoporotic fractures including hip fractures [4] while obesity has been associated with a decreased risk of hip fractures [4, 5]. The proposed protective effect of overall obesity has been challenged since abdominal obesity has been found to associate with increased risk of hip fractures independently of BMI $[6,7]$. A few previous studies on postmenopausal, mostly older, women have also suggested that gynoid fat pattern, as measured by hip circumference (HC), may be inversely associated with risk of hip fracture [6-8] further supporting the relevance of regional fat distribution. Nevertheless, the inverse association between HC and risk of hip fracture has not been reported independently of BMI, suggesting that part of the protective effect of higher HC can be attributed to total body fatness. There are different mechanisms which could explain the protection by a large hip, for instance through a "cushioning effect" from excess soft tissue on a large hip [9]; a higher body weight with larger HC, increasing the mechanical force on the lower limbs and resulting in stronger bones [10]; and/or higher estrogen levels related to the fat tissue that may protect against low bone mineral density [11].

In this study, we examined the association between $\mathrm{HC}$ measured at different points in time in relation to risk of hip fracture in a population-based cohort of Swedish women. Furthermore, we explored whether associations with HC differed according to type of fracture, i.e., hip versus other sites.

\section{Materials and methods}

\section{PPSWG cohort}

The Prospective Population Study of Women in Gothenburg (PPSWG) is a population-based study of women that was initiated in 1968-1969 by recruiting a representative sample of 1622 women born in 1908, 1914, 1918, 1922, and 1930 and living in Gothenburg [12]. A total of 1462 women (90\% of those invited) participated in the 1968-1969 examination. These women were re-invited to follow-up examinations in 1974-1975, 1980-1981, 1992-1993, 2000-2002, and 20052006. Women who underwent their first measurements of HC either in 1968-1969 $(n=1405)$ or in 1974-1975 $(n=47)$ were included in the analysis of baseline HC. A total of 1329 women had at least one additional measure of $\mathrm{HC}$ taken before the date of a hip fracture event or censoring. The last available measure, hereafter called proximal measure of $\mathrm{HC}$, was used to compare effects of proximal versus earlier baseline measure of $\mathrm{HC}$ on the risk of hip fracture. Table $\mathrm{S} 1$ gives an overview of timing of baseline and proximal measure of hip circumference, respectively, and the number of women at each measuring point by birth year. All subjects gave informed consent to participate. From 1992, all examinations sought and obtained approval from the regional ethics review board in Gothenburg, formerly the Ethics Committee at the University of Gothenburg (registration number T453-04 for the examination in 2005-2006).

\section{Anthropometric measures and other variables}

Subjects, wearing underwear, were weighed on a balance scale and measured for height on a fixed stadiometer. BMI was calculated as weight $(\mathrm{kg})$ divided by height $(\mathrm{m})$ squared. BMI was categorized into underweight (BMI $<20.0 \mathrm{~kg} / \mathrm{m}^{2}$ ), normal weight (BMI $\geq 20.0$ to $<25$ ), overweight (BMI $\geq 25$ to $<30$ ), and obesity (BMI $\geq 30$ ). Waist circumference (WC) was measured midway between the lowest rib bone and the iliac crest and $\mathrm{HC}$ at the point over the buttock corresponding to the largest circumference. Three women with implausible values for proximal $\mathrm{HC}(>165 \mathrm{~cm})$ were excluded from the analyses. The final sample for analysis consisted of 1452 women with baseline $\mathrm{HC}$ as exposure of which 1326 women also had values for proximal HC. Waist-to-hip ratio (WHR) was calculated as WC divided by HC.

Information on potential confounders was based on questionnaires and interviews at the respective examinations. Leisure-time physical activity (LTPA) distinguished between any physical activity at least $4 \mathrm{~h} /$ week and sedentary behavior. Smokers were categorized according to current smoking status (yes/no). Information on hormonal replacement therapy (HRT) was retrieved from questionnaires and through medical records, and defined as ever using HRT before baseline or proximal examination of $\mathrm{HC}$, respectively. Missing values for smoking $(n=167)$ and LTPA $(n=170)$ at the proximal hip measurement were imputed with the last registered value for the respective variable.

\section{Hip fracture ascertainment}

Using personal identification numbers, the women were followed through the Swedish Hospital Discharge Register until end of follow-up by May 1, 2015. Cases of incident hip fractures were identified according to ICD8/9 code 820 and ICD10 code S72. Other incident fractures were identified according to ICD8/9 codes 800-819 and 821-829 and ICD10 codes S02, S12, S22, S32, S42, S52, S62, S82, and S92. High validity of diagnoses from the Swedish Hospital Discharge Register has been shown, with a positive predictive value of 98.4\% for hip fractures [13].

\section{Statistical analyses}

Differences in characteristics across quintiles of baseline and proximal HC, respectively, were examined by analysis of variance for continuous variables and by $\chi^{2}$ test for categorical variables. We used the Cox proportional hazard model to 
investigate whether $\mathrm{HC}$ was associated with incident hip fracture. Survival time from examination of HC (either baseline or proximal measure) until date of hip fracture or censoring due to death, emigration from Sweden, or end of follow-up was used as underlying time-metric. $\mathrm{HC}$ was parameterized in terms of quintiles (Q), with the lowest Q (Q1) as reference. The baseline models were adjusted for baseline values of age, BMI (either categorical or continuous), height, LTPA, smoking, and HRT, and with updated covariate values in proximal analyses. To further explore the association between $\mathrm{HC}$ and risk of fracture (hip fracture and fractures at other sites) we performed Cox proportional hazard regression based on restricted cubic splines [14]. Four knots were automatically assigned at $89,96,102$, and $112 \mathrm{~cm}$ in baseline analyses and at $88,93,107$, and $117 \mathrm{~cm}$ in proximal analyses, and the mean value of $\mathrm{HC}$ was chosen as the reference $(100 \mathrm{~cm}$ at baseline and $101 \mathrm{~cm}$ at proximal $\mathrm{HC}$ measurement).

The proportional hazards assumption (PHA) of the Cox proportional hazards model was evaluated by including interaction terms between category of $\mathrm{HC}$ (quintiles of baseline or proximal HC) and survival time until hip fracture or censoring. These tests did not indicate violation of the PHA $(p>0.13$ for all interaction terms).

Interactions between quintiles of $\mathrm{HC}$ and age, BMI categories, height, smoking, LTPA, and HRT were analyzed by inclusion of the corresponding product term in the model. In baseline analysis, we also tested the interaction between $\mathrm{HC}$ and menopausal status, with and without concurrent adjustment for age. In addition, interaction terms were also tested with dichotomized variables for age (baseline at 50 years, proximal at 70 years) and height (baseline $164 \mathrm{~cm}$, proximal $161 \mathrm{~cm})$.

To investigate the correlation of effect estimates, we performed a linear regression of survival time until hip fracture or censoring on all factors included in the model, disregarding censoring status. Variance inflation factors (VIF:s) were calculated for all variables. Sensitivity analyses were performed by excluding cases occurring within 1 year after examination. No case occurred during the first year after baseline measurement of $\mathrm{HC}$ while 14 women experienced a hip fracture in the year after the proximal measurement of HC. Baseline analyses were also repeated after exclusion of women without followup measurements $(n=126)$. Statistical analyses were performed in SAS, version 9.3 (SAS Institute, Cary, NC). A $p$ value of less than 0.05 was considered significant (two-sided test).

\section{Results}

At baseline examination, women were on average 47.6 years old (range 38.3-61.4). During a mean follow-up of 32.8 years (47,600 person-years), 257 women suffered a hip fracture at a mean age of 79.5 years (range 53.6-97.4). Proximal HC was on average measured 24 years after baseline examination at a mean age of 71.7 years (range 44.3-92.8). From proximal examination of $\mathrm{HC}$, the women were followed for a mean of 9.6 years (12,800 person-years), and during this time, 232 incident cases of hip fractures occurred at a mean age of 80.3 years (range 56.7-97.4).

Table 1 shows baseline and proximal characteristics of the whole study population, as well as by quintile of baseline and proximal HC, respectively. In both baseline and proximal analyses, women with larger $\mathrm{HC}$ were older, heavier, and taller, and had a higher BMI and larger WC and WHR. Additionally, at both time points, women with larger $\mathrm{HC}$ were less likely to smoke and were more sedentary. At baseline, women with lower education had larger HC, while no association was seen between education and the proximal measure of HC. The correlation between HC and BMI was high at both time points (baseline $r=0.87, p<0.001$; proximal $r=0.86$, $p<0.001)$. In regression models for survival until censoring or hip fracture described below, VIF:s were just above 1 for all variables except quintiles of $\mathrm{HC}$ and categories of BMI for which they were $<4.2(<4.9$ in models with continuous BMI), indicating moderate collinearity.

Age-adjusted analyses showed an inverse association between baseline $\mathrm{HC}$ and risk of hip fracture (Table 2). When controlling also for BMI and height, the association was strengthened and did not change upon further adjustment for LTPA, smoking, and HRT. Categories of baseline BMI were not associated with risk of hip fracture in the mutually adjusted model (Table 2). Adjusted for age only, neither BMI categories $(\mathrm{HR}(95 \% \mathrm{CI})<20.0,1.38(0.94-2.03) ; \geq 20.0$ to $<25$, 1 (ref); $\geq 25$ to $<30,0.85(0.63-1.15) ; \geq 30,1.01(0.62-1.64)$ ) nor continuous BMI (HR (95\% CI) 0.97 (0.93-1.01)) predicted hip fracture. Including BMI as a continuous variable, instead of a categorical variable, did not change the estimates of $\mathrm{HC}$ on the risk of hip fracture (data not shown). No significant interactions were found between baseline $\mathrm{HC}$ and any of the covariates (data not shown), independent of whether BMI was included as a categorical or as a continuous variable.

To examine whether the relation between $\mathrm{HC}$ and risk of hip fracture may change with age, we investigated the association between a proximal measure of $\mathrm{HC}$ and risk of hip fracture. Age-adjusted analyses showed that the HC measured proximally to the hip fracture was also associated with decreased risk (Table 3). Adjusting for BMI and height attenuated the association, while additional adjustment for LTPA, smoking, and HRT did not further affect the estimates. In contrast to baseline measures, the associations between proximal HC and hip fracture were fully explained by the inverse association with proximal BMI (Fig. 1, Table 3). Women with overweight at proximal measure of $\mathrm{HC}$ had a lower risk of hip fractures compared to women with normal weight, which remained significant also after adjustment for LTPA, smoking, 
Table 1 Baseline and proximal characteristics by quintile of hip circumference in women in the PPSWG study

\begin{tabular}{|c|c|c|c|c|c|c|c|}
\hline & \multirow[t]{2}{*}{ Total sample } & \multicolumn{5}{|c|}{ Quintile of hip circumference } & \multirow[t]{2}{*}{$P$ value } \\
\hline & & 1 & 2 & 3 & 4 & 5 & \\
\hline \multicolumn{8}{|c|}{ Number of participants $(n)$} \\
\hline Baseline & 1452 & 271 & 345 & 249 & 313 & 274 & \\
\hline Proximal & 1326 & 268 & 239 & 289 & 285 & 245 & \\
\hline \multicolumn{8}{|c|}{ Hip circumference $(\mathrm{cm})$, range } \\
\hline Baseline & $79-136$ & 79-93 & $94-97$ & $98-100$ & $101-105$ & $106-136$ & \\
\hline Proximal & $74-145$ & $74-93$ & $94-97$ & $98-102$ & $103-108$ & $109-145$ & \\
\hline \multicolumn{8}{|c|}{ Age (years), mean (SD) } \\
\hline Baseline & $47.6(6.3)$ & $47.0(6.2)$ & $47.2(6.0)$ & $47.1(5.9)$ & $48.5(6.6)$ & $48.3(6.4)$ & 0.005 \\
\hline Proximal & $71.7(10.9)$ & 70.5 (11.6) & $70.3(11.5)$ & $72.8(10.5)$ & $71.8(10.5)$ & $72.9(9.9)$ & 0.007 \\
\hline \multicolumn{8}{|c|}{ Weight (kg), mean (SD) } \\
\hline Baseline & $64.5(10.8)$ & $52.8(5.0)$ & $59.5(4.1)$ & $62.9(4.2)$ & $68.3(4.9)$ & $79.7(10.6)$ & $<0.001$ \\
\hline Proximal & $67.2(12.7)$ & $53.2(6.0)$ & $60.9(5.5)$ & $66.7(6.4)$ & $72.1(6.7)$ & $83.8(12.4)$ & $<0.001$ \\
\hline \multicolumn{8}{|c|}{ Height (cm), mean (SD) } \\
\hline Baseline & $163.6(5.9)$ & $161.6(5.8)$ & $163.0(5.6)$ & $163.5(5.8)$ & $164.4(5.6)$ & $165.5(5.9)$ & $<0.001$ \\
\hline Proximal & $161.1(6.2)$ & $159.3(6.1)$ & $161.0(5.6)$ & $161.8(6.2)$ & $161.3(6.3)$ & $161.9(6.3)$ & $<0.001$ \\
\hline \multicolumn{8}{|c|}{ BMI $\left(\mathrm{kg} / \mathrm{m}^{2}\right)$, mean $(\mathrm{SD})$} \\
\hline Baseline & $24.1(3.7)$ & $20.2(1.8)$ & $22.4(1.7)$ & $23.6(1.8)$ & $25.3(2.1)$ & $29.1(3.7)$ & $<0.001$ \\
\hline Proximal & $25.9(4.6)$ & $21.0(2.4)$ & $23.5(2.2)$ & $25.5(2.2)$ & $27.7(2.3)$ & $32.0(4.3)$ & $<0.001$ \\
\hline \multicolumn{8}{|c|}{ Waist $(\mathrm{cm})$, mean $(\mathrm{SD})$} \\
\hline Baseline & $73.8(8.5)$ & $66.1(4.5)$ & $70.4(4.7)$ & $72.5(4.9)$ & $76.3(5.7)$ & $84.0(9.6)$ & $<0.001$ \\
\hline Proximal & $84.9(11.8)$ & $72.8(7.0)$ & $78.6(6.4)$ & $84.6(7.7)$ & $89.4(7.1)$ & $99.7(9.6)$ & $<0.001$ \\
\hline \multicolumn{8}{|c|}{ Waist-hip ratio, mean (SD) } \\
\hline Baseline & $0.74(0.05)$ & $0.73(0.04)$ & $0.74(0.05)$ & $0.73(0.05)$ & $0.74(0.05)$ & $0.75(0.07)$ & $<0.001$ \\
\hline Proximal & $0.84(0.07)$ & $0.81(0.07)$ & $0.82(0.07)$ & $0.85(0.08)$ & $0.85(0.07)$ & $0.86(0.07)$ & $<0.001$ \\
\hline \multicolumn{8}{|c|}{ Education above basic level, $n(\%)$} \\
\hline Baseline & $439(30.3)$ & $94(35.0)$ & $117(34.0)$ & $84(33.9)$ & $80(25.6)$ & $64(23.4)$ & 0.003 \\
\hline Proximal & $405(30.6)$ & $91(34.1)$ & $80(33.6)$ & $92(31.8)$ & $73(25.7)$ & $69(28.2)$ & 0.16 \\
\hline \multicolumn{8}{|c|}{ Smoker, $n(\%)$} \\
\hline Baseline & $589(40.6)$ & $156(57.8)$ & $153(44.5)$ & $100(40.2)$ & $104(33.2)$ & $76(27.7)$ & $<0.001$ \\
\hline Proximal & $328(24.8)$ & $96(36.0)$ & $71(29.7)$ & $66(22.9)$ & $57(20.1)$ & $38(15.5)$ & $<0.001$ \\
\hline \multicolumn{8}{|c|}{ Sedentary, $n(\%)$} \\
\hline Baseline & $265(18.3)$ & $54(19.9)$ & $59(17.1)$ & $27(10.8)$ & $70(22.4)$ & $55(20.1)$ & 0.007 \\
\hline Proximal & $340(25.6)$ & $68(25.4)$ & $54(22.6)$ & $61(21.1)$ & $69(24.2)$ & $88(35.9)$ & 0.0011 \\
\hline \multicolumn{8}{|c|}{ Ever use of $\mathrm{HRT}^{\mathrm{b}}, n(\%)$} \\
\hline Baseline & $56(3.9)$ & $7(2.6)$ & $20(5.8)$ & $9(3.6)$ & $13(4.2)$ & $7(2.6)$ & 0.20 \\
\hline Proximal & 189 (14.3) & 44 (16.4) & $32(13.4)$ & $36(12.5)$ & $36(12.6)$ & $41(16.7)$ & 0.44 \\
\hline
\end{tabular}

${ }^{\text {a }} P$ values across categories of hip circumference from analysis of variance $\left(F\right.$ test) for continuous variables and from $\chi^{2}$ test for categorical variables

${ }^{\mathrm{b}} H R T$ hormone replacement therapy

and HRT (Table 3). No interactions were found between proximal $\mathrm{HC}$ and other covariates (data not shown).

To explore whether the effect of a large hip was specific to hip fractures, we investigated the association with fractures at other sites than the hip. During follow-up from baseline measurement of HC, a total of 336 cases of fractures at other sites requiring in-patient hospital care were registered. Figure 2 illustrates the association between baseline $\mathrm{HC}$ and risk of hip fracture (top) in comparison to risk of fractures at other sites (bottom), adjusted for covariates. While $\mathrm{HC}$ was inversely related to risk of hip fracture, a U-shaped risk curve was found for fractures at other sites than hip with significantly increased risk at larger hips as compared to mean $\mathrm{HC}$ $(100 \mathrm{~cm})$. 
Table 2 Hazard ratios and 95\% confidence intervals for the association between baseline hip circumference and hip fracture in Swedish women $(n=1452)$ (Prospective Population Study of Women in Gothenburg) and mutually adjusted covariates

\begin{tabular}{|c|c|c|c|c|}
\hline & \multirow[t]{2}{*}{ Number of cases } & \multicolumn{3}{|c|}{ Covariate adjustment for } \\
\hline & & Age & + BMI and height & $\begin{array}{l}\text { + physical activity, } \\
\text { smoking, and HRT }\end{array}$ \\
\hline \multicolumn{5}{|c|}{ Hip circumference $(\mathrm{cm})$, quintiles: } \\
\hline$\leq 93$ & 54 & 1 (ref) & 1 (ref) & 1 (ref) \\
\hline $94-97$ & 72 & $0.88(0.62-1.25)$ & $0.79(0.53-1.19)$ & $0.85(0.56-1.27)$ \\
\hline $98-100$ & 37 & $0.62(0.40-0.93)$ & $0.53(0.33-0.87)$ & $0.59(0.36-0.96)$ \\
\hline $101-105$ & 49 & $0.65(0.44-0.96)$ & $0.51(0.30-0.86)$ & $0.57(0.34-0.96)$ \\
\hline$\geq 106$ & 45 & $0.74(0.50-1.10)$ & $0.49(0.26-0.92)$ & $0.58(0.31-1.10)$ \\
\hline Age (years) & 257 & $1.13(1.10-1.15)$ & $1.13(1.11-1.16)$ & $1.14(1.11-1.17)$ \\
\hline \multicolumn{5}{|l|}{ BMI $\left(\mathrm{kg} / \mathrm{m}^{2}\right)$} \\
\hline$<20$ & 31 & - & $0.98(0.62-1.55)$ & $0.97(0.61-1.54)$ \\
\hline$\geq 20$ to $<25$ & 146 & - & $1(\mathrm{ref})$ & 1 (ref) \\
\hline$\geq 25$ to $<30$ & 61 & - & $1.19(0.79-1.78)$ & $1.14(0.76-1.72)$ \\
\hline$\geq 30$ & 19 & - & $1.48(0.77-2.82)$ & $1.43(0.75-2.74)$ \\
\hline Height (cm) & 257 & - & $1.04(1.02-1.07)$ & $1.04(1.01-1.06)$ \\
\hline LTPA $^{\mathrm{a}}$ & 257 & - & - & $0.84(0.61-1.16)$ \\
\hline Smoking ${ }^{\mathrm{b}}$ & 257 & - & - & $1.59(1.23-2.07)$ \\
\hline HRT use ${ }^{c}$ & 257 & - & - & $0.87(0.45-1.70)$ \\
\hline
\end{tabular}

${ }^{\text {a }}$ LTPA leisure time physical activity. Reference category = inactive

${ }^{\mathrm{b}}$ Reference category $=$ non-smokers

${ }^{\mathrm{c}} H R T$ hormone replacement therapy. Reference category = non-use
Sensitivity analyses excluding 14 cases that occurred during the first year after proximal measurement of $\mathrm{HC}$ did not affect the results (data not shown). To improve comparability of the results from baseline and proximal analyses, 126 women who only participated in the baseline examination were excluded from baseline analyses, but this did not change the results reported in Table 2 (data not shown).

\section{Discussion}

In this study of a longitudinally followed population-based cohort of Swedish women, we showed that a large HC was related to a lower risk for a future hip fracture, independent of age at measurement of $\mathrm{HC}$ and regardless if $\mathrm{HC}$ was measured long before the hip fracture or more closely in time. Our study further showed that, depending on the age when $\mathrm{HC}$ was measured, there seems to be a difference in how BMI affects the association between $\mathrm{HC}$ and risk of hip fracture, and in the independent risk of hip fracture related to BMI. Using baseline $\mathrm{HC}$, measured when the majority of women were 40 to 50 years old, the association with hip fracture was independent of BMI and height. In contrast, when using a more recent measure of $\mathrm{HC}$, taken when most of the women were 60 to 80 years old, adjustment for BMI and height resulted in attenuation to non-significance, suggesting no independent protection by large hips at these ages.
Our results based on proximal measurements of HC, i.e., in older women, are in agreement with results from previous studies, which included only postmenopausal women, and also reported an inverse association between $\mathrm{HC}$ and risk of hip fracture that was attenuated when adjusting for BMI [7, 8], and in one study also for height [6]. Higher levels of estrogen in women with high BMI, because of the production of estrogen in adipose tissue [15], may provide an explanation for the attenuation after adjustment for BMI. However, in our study, associations were essentially similar before and after adjustment for HRT suggesting little influence from estrogen therapy. This could be explained by the fact that, even though current use of HRT has been shown to reduce the risk of hip fracture, the effect is substantially decreased after a time without HRT $[16,17]$. Considering the advanced age at hip fracture, few women in this study were likely using HRT close in time to the event.

The specific finding of an independent protection against hip fracture by large hips in middle-aged women is novel. One explanation for these age-related differences could stem from the independent impact of BMI on the risk of hip fracture. At younger ages, larger $\mathrm{HC}$ at similar $\mathrm{BMI}$ is protective because this indicates less central adiposity, and visceral abdominal fat has been shown to associate negatively to bone structure and strength in young females [18]. At high ages, low BMI is mainly a marker of frailty which confers an excess risk of hip fracture [19] independent of HC. An additional 
Table 3 Hazard ratios and 95\% confidence intervals for the association between proximal measure of hip circumference and hip fracture in Swedish women $(n=1326)$ (Prospective Population Study of Women in Gothenburg) and mutually adjusted covariates

\begin{tabular}{|c|c|c|c|c|}
\hline & \multirow[t]{2}{*}{ Number of cases } & \multicolumn{3}{|c|}{ Covariate adjustment for } \\
\hline & & Age & + BMI and height & $\begin{array}{l}\text { + Physical activity, } \\
\text { smoking, and HRT }\end{array}$ \\
\hline \multicolumn{5}{|c|}{ Hip circumference (cm), quintiles: } \\
\hline$\leq 93$ & 57 & 1 (ref) & 1 (ref) & 1 (ref) \\
\hline 94-97 & 52 & $0.88(0.60-1.28)$ & $0.94(0.62-1.42)$ & $0.95(0.63-1.45)$ \\
\hline 98-102 & 45 & $0.59(0.40-0.88)$ & $0.72(0.45-1.16)$ & $0.75(0.46-1.20)$ \\
\hline $103-108$ & 50 & $0.67(0.46-0.99)$ & $0.98(0.57-1.68)$ & $1.05(0.61-1.80)$ \\
\hline$\geq 109$ & 28 & $0.43(0.27-0.68)$ & $0.63(0.31-1.27)$ & $0.67(0.34-1.34)$ \\
\hline Age (years) & 232 & $1.07(1.05-1.09)$ & $1.08(1.06-1.09)$ & $1.09(1.07-1.10)$ \\
\hline \multicolumn{5}{|l|}{ BMI $\left(\mathrm{kg} / \mathrm{m}^{2}\right)$} \\
\hline$<20.0$ & 23 & - & $1.31(0.80-2.16)$ & $1.30(0.79-2.15)$ \\
\hline$\geq 20.0$ to $<25$ & 113 & - & 1 (ref) & 1 (ref) \\
\hline$\geq 25$ to $<30$ & 68 & - & $0.65(0.44-0.97)$ & $0.66(0.44-0.98)$ \\
\hline$\geq 30$ & 28 & - & $0.66(0.35-1.23)$ & $0.68(0.37-1.25)$ \\
\hline Height (cm) & 232 & - & $1.03(1.00-1.05)$ & $1.03(1.00-1.05)$ \\
\hline $\mathrm{LTPA}^{\mathrm{a}}$ & 232 & - & - & $1.10(0.80-1.51)$ \\
\hline Smoking ${ }^{\mathrm{b}}$ & 232 & - & - & $1.69(1.23-2.32)$ \\
\hline HRT use ${ }^{c}$ & 232 & - & - & $0.85(0.57-1.27)$ \\
\hline
\end{tabular}

${ }^{\text {a }}$ LTPA leisure time physical activity. Reference category = inactive

${ }^{\mathrm{b}}$ Reference category $=$ non-smokers

${ }^{\mathrm{c}} H R T$ hormone replacement therapy. Reference category = non-use explanation may be that the composition of fat and lean tissue on the hips changes with age, as it is well recognized that agerelated muscle loss starts already in young adulthood [20]. Hence, the protection of large hips at middle age may depend on better muscular support than for the same hip size at older ages.

It has also been suggested that the protection from having a large hip could be explained by a simple padding effect of excess soft tissue absorbing energy from a fall and thus protecting against hip fracture [9]. If the protection from a large hip was due to padding, attenuation after adjustment for BMI, as a proxy for fat mass, could be expected. However, the major attenuation seen in the proximal analyses, in addition to the independent effect of BMI, indicate that it is indeed BMI that drives the association between $\mathrm{HC}$ and risk of hip fracture at older ages. This suggests that protection from overall body size may be more important than that from body shape in the elderly. Several previous studies of postmenopausal women with age ranging from 50 to 79 have reported lower rates of hip fractures in subjects with higher BMI [7, 8, 21-24]. Furthermore, if physical protection by a large hip was occurring, the effect would have been expected to be stronger for the proximal measures of $\mathrm{HC}$ as compared to the earlier baseline HC, whereas after adjustment for BMI and other covariates, the opposite was observed in our analyses. Taken together, this implies that the protection from having a large hip is likely not due to a simple padding effect. However, the independent distant effect of baseline $\mathrm{HC}$ suggests protection from a large hip at younger ages which may potentially be explained by intrinsic factors influencing bone strength and subsequent risk of fractures. Such factors could for example include levels of various hormones and inflammatory markers [25], as well as hip geometry parameters [26] that might have contributed to the protective effect of a large hip in this age group.

Previously, we showed that a large $\mathrm{HC}$ was associated with a decreased risk of diabetes, myocardial infarction (MI), and cardiovascular disease (CVD) as well as a decreased risk of mortality in the same cohort [27]. Hip fracture is associated with a more than fivefold increased risk of mortality in women during the first 3 months after the fracture and with excess annual mortality persisting many years [28]. Hence, it could be hypothesized that one reason for the previously observed decreased risk of allcause mortality in women with larger $\mathrm{HC}$, in addition to the decrease in mortality related to CVD, could be attributed to the protection against hip fractures. In the context of increased longevity of women with large HC [27], it may furthermore be presumed that, due to the increasing rate of hip fractures with age, the inverse association between $\mathrm{HC}$ and risk of hip fracture is underestimated. Thus, the true protection from a large HC may even be stronger. Identification of easy-to-measure risk factors for hip fracture is necessary for screening and targeted prevention efforts. In a sub-sample of the present cohort, Jonasson et al. showed that dental radiographs measuring trabeculation of the 

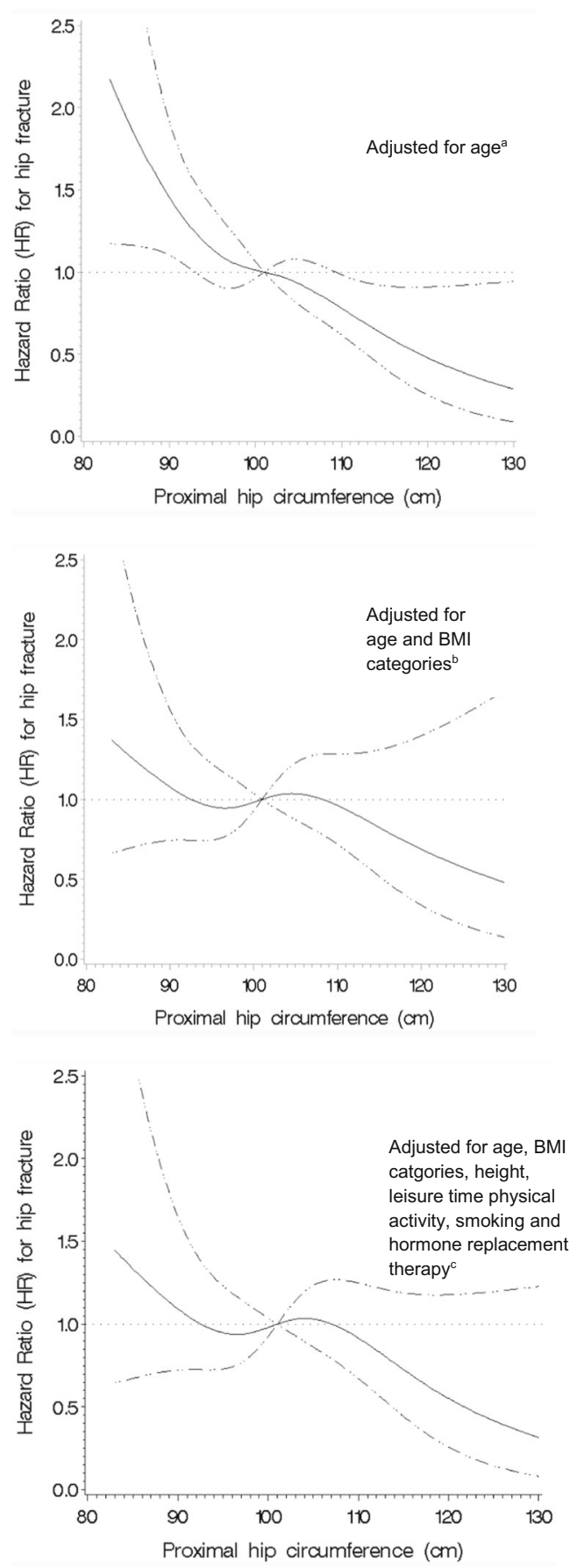

Fig. 1 Hazard ratio (HR) for proximal hip circumference in relation to risk of hip fractures at different levels of adjustment ( $n$ cases/total, 232/ 1326). Dark line represents HR. Dotted lines represent $95 \%$ confidence interval for the HR. Reference value for hip circumference was set at mean hip circumference $(101 \mathrm{~cm})$. ${ }^{a}$ Test for curvature $P=0.65$, test for overall significance $P=0.003$, test for linearity $P<0.001$. ${ }^{\mathrm{b}}$ Test for curvature $P=0.50$, test for overall significance $P=0.55$, test for linearity $P=0.39$. ${ }^{\mathrm{c}}$ Test for curvature $P=0.31$, test for overall significance $P=0.29$, test for linearity $P=0.24$

jawbone were highly predictive of fracture risk [29]. Thus, dental x-rays and HC, two standard measurements, could potentially be used together to further
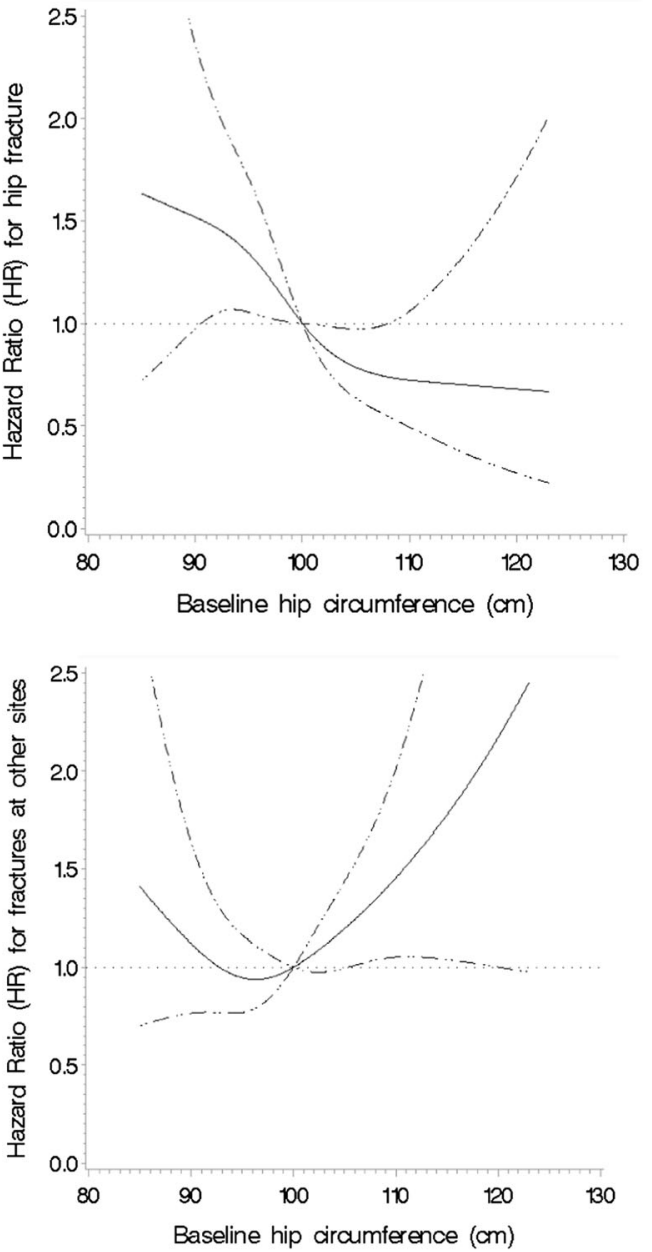

Fig. 2 Hazard ratio (HR) for baseline hip circumference in relation to risk of hip fractures ( $n$ cases/total, 257/1452) and fractures at other sites ( $n$ cases/total, 331/1421). Models were adjusted for baseline values of age, BMI categories, height, smoking, leisure time physical activity, and hormone replacement therapy. Dark line represents HR. Dotted lines represent 95\% confidence interval for the HR. Reference value for hip circumference was set at mean hip circumference $(100 \mathrm{~cm}) .{ }^{\text {a }}$ Test for curvature $P=0.49$, test for overall significance $P=0.09$, test for linearity $P<0.05$. ${ }^{\mathrm{b}}$ Test for curvature $P=0.07$, test for overall significance $P=0.07$, test for linearity $P=0.20$

improve identification of women in mid-life with an increased risk of suffering a future hip fracture.

Strengths of our study include the longitudinal design with a population-based sample followed over many years and with repeated measures allowing investigation of the hip fracture risk related to both baseline and more proximal measures of HC. Moreover, the anthropometric exposure measurements were taken in a standardized way by trained nurses and outcome information originates from high quality registers. However, a limitation is that the register data did not allow us to distinguish between traumatic and osteoporotic fractures. Inclusion of fractures due to accidents, unrelated to anthropometry, may have attenuated our results and led to wider confidence intervals. It should also be noted that register coverage of the heterogeneous group 
of fractures at other sites than hip may be incomplete since some of these fractures do not require inpatient hospital care. Furthermore, we cannot rule out the possibility of residual confounding by body composition (which was not measured) or anthropometric changes taking place after the last examination. Finally, the collinearity between HC and BMI must be acknowledged with consequences for the ability to separate the effect of $\mathrm{HC}$ on risk of hip fracture from that of BMI.

\section{Conclusion}

In this study, we showed that a large $\mathrm{HC}$ is protective specifically against hip fracture, irrespective of if $\mathrm{HC}$ was measured in middle age or old age, but that a high BMI seems to fully account for this effect in older women suggesting that padding of additional tissue on the hips is not the main mechanism. The independent protective effect on hip fracture risk seen in middle-aged women with large hips may depend on better muscular support or intrinsic factors influencing bone strength.

Acknowledgements This work was funded by the Swedish Research Council FORTE, through its support of EpiLife Center of Excellence.

\section{Compliance with ethical standards}

\section{Conflicts of interest None.}

Open Access This article is distributed under the terms of the Creative Commons Attribution-NonCommercial 4.0 International License (http:// creativecommons.org/licenses/by-nc/4.0/), which permits any noncommercial use, distribution, and reproduction in any medium, provided you give appropriate credit to the original author(s) and the source, provide a link to the Creative Commons license, and indicate if changes were made.

\section{References}

1. Kanis JA, Oden A, McCloskey EV, Johansson H, Wahl DA, Cooper C, Epidemiology IOFWGo, Quality of L (2012) A systematic review of hip fracture incidence and probability of fracture worldwide. Osteoporos Int 23(9):2239-2256. https://doi.org/10. 1007/s00198-012-1964-3

2. Carpintero P, Caeiro JR, Carpintero R, Morales A, Silva S, Mesa M (2014) Complications of hip fractures: a review. World J Orthop 5(4):402-411. https://doi.org/10.5312/wjo.v5.i4.402

3. Santesso N, Carrasco-Labra A, Brignardello-Petersen R (2014) Hip protectors for preventing hip fractures in older people. Cochrane Database Syst Rev 3:CD001255. https://doi.org/10.1002/ 14651858.CD001255.pub5

4. Johansson H, Kanis JA, Oden A, McCloskey E, Chapurlat RD, Christiansen C, Cummings SR, Diez-Perez A, Eisman JA, Fujiwara S, Gluer CC, Goltzman D, Hans D, Khaw KT, Krieg MA, Kroger H, LaCroix AZ, Lau E, Leslie WD, Mellstrom D, Melton LJ 3rd, O'Neill TW, Pasco JA, Prior JC, Reid DM, Rivadeneira F, van Staa T, Yoshimura N, Zillikens MC (2014) A meta-analysis of the association of fracture risk and body mass index in women. J Bone Miner Res 29(1):223-233. https://doi. org/10.1002/jbmr.2017

5. Tang X, Liu G, Kang J, Hou Y, Jiang F, Yuan W, Shi J (2013) Obesity and risk of hip fracture in adults: a meta-analysis of prospective cohort studies. PLoS One 8(4):e55077. https://doi.org/10. 1371/journal.pone.0055077

6. Meyer HE, Willett WC, Flint AJ, Feskanich D (2016) Abdominal obesity and hip fracture: results from the Nurses' health study and the health professionals follow-up study. Osteoporos Int 27(6): 2127-2136. https://doi.org/10.1007/s00198-016-3508-8

7. Sogaard AJ, Holvik K, Omsland TK, Tell GS, Dahl C, Schei B, Falch JA, Eisman JA, Meyer HE (2014) Abdominal obesity increases the risk of hip fracture. A population-based study of 43 000 women and men aged 60-79 years followed for 8 years. Cohort of Norway. J Intern Med 277(3):306-317. https://doi.org/ 10.1111/joim.12230

8. Parker ED, Pereira MA, Virnig B, Folsom AR (2008) The association of hip circumference with incident hip fracture in a cohort of postmenopausal women: the Iowa Women's health study. Ann Epidemiol 18(11):836-841. https://doi.org/10.1016/j.annepidem. 2008.07.007

9. Robinovitch SN, McMahon TA, Hayes WC (1995) Force attenuation in trochanteric soft tissues during impact from a fall. J Orthop Res 13(6):956-962. https://doi.org/10.1002/jor.1100130621

10. Edelstein SL, Barrett-Connor E (1993) Relation between body size and bone mineral density in elderly men and women. Am J Epidemiol 138(3):160-169. https://doi.org/10.1093/ oxfordjournals.aje.a116842

11. Filip R, Raszewski G (2009) Bone mineral density and bone turnover in relation to serum leptin, alpha-ketoglutarate and sex steroids in overweight and obese postmenopausal women. Clin Endocrinol 70(2):214-220. https://doi.org/10.1111/j.1365-2265.2008.03313.x

12. Bengtsson C, Blohme G, Hallberg L, Hällström T, Isaksson B, Korsan-Bengtsen K, Rybo G, Tibblin E, Tibblin G, Westerberg H (1973) The study of women in Gothenburg 1968-1969 - a population study. General design, purpose and sampling results. Acta Med Scand 193(4):311-318

13. Ludvigsson JF, Andersson E, Ekbom A, Feychting M, Kim JL, Reuterwall C, Heurgren M, Olausson PO (2011) External review and validation of the Swedish national inpatient register. BMC Public Health 11(1):450. https://doi.org/10.1186/1471-2458-11450

14. Li R, Hertzmark E, Louie M, Chen L, Spiegelman D (2011) The SAS LGTPHCURV9 Macro. http://www.hsph.harvard.edu/faculty/ donna-spiegelman/software. Accessed 2012 Oct 15

15. Siiteri PK (1987) Adipose tissue as a source of hormones. Am J Clin Nutr 45(1 Suppl):277-282. https://doi.org/10.1093/ajcn/45.1. 277

16. Corrao G, Zambon A, Nicotra F, Conti V, Nappi RE, Merlino L (2008) Issues concerning the use of hormone replacement therapy and risk of fracture: a population-based, nested case-control study. Br J Clin Pharmacol 65(1):123-129. https://doi.org/10.1111/j.13652125.2007.02904.x

17. Michaelsson K, Baron JA, Farahmand BY, Johnell O, Magnusson C, Persson PG, Persson I, Ljunghall S (1998) Hormone replacement therapy and risk of hip fracture: population based case-control study. The Swedish hip fracture study group. BMJ 316(7148): 1858-1863. https://doi.org/10.1136/bmj.316.7148.1858

18. Gilsanz V, Chalfant J, Mo AO, Lee DC, Dorey FJ, Mittelman SD (2009) Reciprocal relations of subcutaneous and visceral fat to bone structure and strength. J Clin Endocrinol Metab 94(9):3387-3393. https://doi.org/10.1210/jc.2008-2422

19. Ensrud KE, Ewing SK, Taylor BC, Fink HA, Stone KL, Cauley JA, Tracy JK, Hochberg MC, Rodondi N, Cawthon PM, Study of Osteoporotic Fractures Research G (2007) Frailty and risk of falls, 
fracture, and mortality in older women: the study of osteoporotic fractures. J Gerontol A Biol Sci Med Sci 62(7):744-751

20. Dodds RM, Roberts HC, Cooper C, Sayer AA (2015) The epidemiology of sarcopenia. J Clin Densitom 18(4):461-466. https://doi. org/10.1016/j.jocd.2015.04.012

21. DiPietro L, Welch GA, Davis DR, Drane JW, Macera CA (1993) Body mass and risk of hip fracture among a national cohort of postmenopausal white women: a reanalysis. Obes Res 1(5):357363. https://doi.org/10.1002/j.1550-8528.1993.tb00013.x

22. Paganini-Hill A, Chao A, Ross RK, Henderson BE (1991) Exercise and other factors in the prevention of hip fracture: the leisure world study. Epidemiology 2(1):16-25. https://doi.org/10.1097/ 00001648-199101000-00004

23. Armstrong ME, Spencer EA, Cairns BJ, Banks E, Pirie K, Green J, Wright FL, Reeves GK, Beral V, Million Women Study C (2011) Body mass index and physical activity in relation to the incidence of hip fracture in postmenopausal women. J Bone Miner Res 26(6): 1330-1338. https://doi.org/10.1002/jbmr.315

24. Prieto-Alhambra D, Premaor MO, Fina Aviles F, Hermosilla E, Martinez-Laguna D, Carbonell-Abella C, Nogues X, Compston JE, Diez-Perez A (2012) The association between fracture and obesity is site-dependent: a population-based study in postmenopausal women. J Bone Miner Res 27(2):294-300. https://doi.org/10.1002/ jbmr.1466

25. Gonnelli S, Caffarelli C, Nuti R (2014) Obesity and fracture risk. Clin Cases Miner Bone Metab 11(1):9-14

26. Broy SB, Cauley JA, Lewiecki ME, Schousboe JT, Shepherd JA, Leslie WD (2015) Fracture risk prediction by non-BMD DXA measures: the 2015 ISCD official positions part 1: hip geometry. J Clin Densitom 18(3):287-308. https://doi.org/10.1016/j.jocd.2015. 06.005

27. Lissner L, Björkelund C, Heitmann BL, Seidell JC, Bengtsson C (2001) Larger hip circumference independently predicts health and longevity in a Swedish female cohort. Obes Res 9(10):644-646. https://doi.org/10.1038/oby.2001.85

28. Haentjens P, Magaziner J, Colon-Emeric CS, Vanderschueren D, Milisen K, Velkeniers B, Boonen S (2010) Meta-analysis: excess mortality after hip fracture among older women and men. Ann Intern Med 152(6):380-390. https://doi.org/10.7326/0003-4819152-6-201003160-00008

29. Jonasson G, Sundh V, Ahlqwist M, Hakeberg M, Björkelund C, Lissner L (2011) A prospective study of mandibular trabecular bone to predict fracture incidence in women: a low-cost screening tool in the dental clinic. Bone 49(4):873-879. https://doi.org/10.1016/j. bone.2011.06.036 